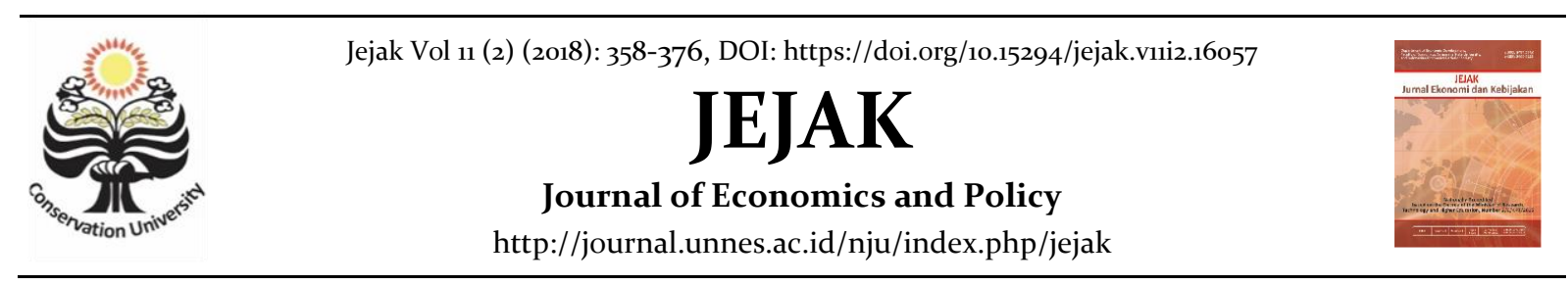

\title{
Infrastructure and Labour Productivity Convergence in Gunungkidul Region
}

\author{
Didit Welly Udjianto' ${ }^{1}$ Joko Susanto ${ }^{2 \bowtie}$, Purwiyanta ${ }^{3}$ \\ ${ }^{123}$ Faculty of Economy and Business, UPN “Veteran” Yogyakarta \\ Permalink/DOI: https://doi.org/10.15294/jejak.v11i2.16057
}

Received: March 2018; Accepted: June 2018; Published: September 2018

\begin{abstract}
:
The paper examines whether labour productivity converges or diverges. This research estimates the convergence of labour productivity, and the effects of infrastructure to support this convergence, based on a set panel data comprising 18 districts in Gunungkidul Regency from 2009 to 2016. The secondary data published by the Statistics of DIY is used in this study. The infrastructure includes educational facilities, health facilities and length of the road. A fixed-effect model presents that there is a process of convergence of labour productivity among districts in Gunungkidul Regency. Moreover, the result shows that infrastructure has a positive effect on labour productivity. This research finds that labour productivity, in the lagging districts, tends to grow faster than advanced ones. Thus, the labour productivity gap between districts will disappear. A better educational and health facilities supports the speed of the knowledge transfer process to generate productive labour. For supporting the convergence of labour productivity, the local government has to improve infrastructure especially in lagging districts. Likewise, improvements in road facilities solve the problem of high-cost distribution to increase labour productivity.
\end{abstract}

Keywords: productivity, labour, convergence, infrastructure

How to Cite: Udjianto, D., Susanto, J., \& Purwiyanta, P. (2018). Infrastructure and Labour Productivity Convergence in Gunungkidul Region. JEJAK: Jurnal Ekonomi dan Kebijakan, 11(2), 358-376. doi:https://doi.org/10.15294/jejak.v11i2.16057

\footnotetext{
Corresponding author :

Address: Jl. SWK 104, Condongcatur, Depok, Sleman, Yogyakarta

E-mail: jk.susanto.68@gmail.com
} 


\section{INTRODUCTION}

Inequality between regions becomes a critical phenomenon that still needs to be studied and analysed to determine the policies that can be taken by the government to improve the community welfare. Inequality can lead to economic inefficiency and injustice thereby undermining social solidarity. Economic inefficiency occurs because, with high inequality, the overall savings rate in the economy tends to be low. Meanwhile, injustice occurs due to the distribution of outputs that tend to be biased toward specific groups. This condition has the potential to cause dysfunctional behaviour. The dysfunctional behaviour marked by the behaviour of a people group deviate from the rules or norms that should be. Dysfunctional community groups are a source of complex social problems.

Inequality occurs because the ownership of resources among community members is heterogeneous. Potential and ability of each social stratum are different. There is a group of community members who have more resources than that other groups. Frequently, the high economic growth is followed by a worsening of income disparities (Wilkinson and Pickett, 2011). Economic growth is often unaffordable for community members. The heterogeneity in resources ownership causes not all members of society to participate in the production process. Those who do not participate in the production process receive no remuneration from the ongoing production process. Thus the variety of endowment factors owned by each region can trigger inequality between regions.

In general, urban areas have better infrastructure, so these areas to become the destination of new investment. The better infrastructure causes the production cost to becomes cheaper. Therefore, the companies will seek to build its plant in locations with good infrastructure. There is a close correlation between investment and location determination. Investments tend to be concentrated in only a few places (Lall et al., 2004) located adjacent to markets or ports.

On the other hand, urban dwellers also have high education and skills so that they get to benefit from urban agglomeration. They can work in the productive sectors and get a high wages. In contrast, the inhabitants of rural areas do not have adequate education and skills so that they cannot find employment in productive sectors. With various considerations in production efficiency, the company determines qualifications of job applicant therefore not all residents can meet the required specifications. Frequently, there are job vacancies in an industry are not filled, while at the same time there are some job seekers who do not get the job they are looking for. Job seekers who do not get a job will be unemployed or forced to work in the informal sector with low productivity. Those with high education and expertise can take advantage of this opportunity, whereas labours with insufficient education and inexperienced will be marginalised. Differences in the level of education and skills between urban dwellers and rural dwellers result in a disparity of labour productivity between the two regions.

Disparities arise due to the concentration of investment in specific areas. In determining the investment location, investors will try to get areas that have high competitiveness. Economically, highly competitive regions will cover cities that have adequate facilities, infrastructure and human resources. Supported by the availability of sufficient infrastructure, the 
production process of goods and services in the region can be done at a lower cost.

Therefore, the effort to reduce the problem of disparity between regions is the development of infrastructure in lagging regions. Infrastructure development includes physical infrastructure and social infrastructure. Physical infrastructure includes such as electricity, drinking water, road, transformation system and telecommunications, while social infrastructure consists of education, training, and health. Development of physical infrastructure will increase the productivity of the economy. Physical infrastructure is a component of capital that can create marginal productivity. The development of physical infrastructure can have a multiplier impact on the economy.

In addition to physical infrastructure, one of the most valuable assets of development is the human resources that cannot be obtained instantly. To obtain qualified human resources takes a long process through serious and sustained investment especially education investment. Education is one of the most important sectors that directly contribute to the development of human resources quality. Education is closely related to economic activity. The main production factors in economic activity are human who controls capital and technology into factors of production.

Based on experience in human resources development, researchers believe that the strategy to raise productivity is to advance the education. The qualified human resources are needed for the progress and success of a nation development. A better learning process is believed to produce graduates who have higher skills. With higher skills, graduates will be able to increase their productivity. Meanwhile, the government, business and the community share an interest in education. One of the educational processes is formal education that takes place in schools both elementary, middle and high school. For society, education is a form of investment. The community will choose the type of education under the goals they want by considering the funds they have.

Likewise, business are concerned with worker productivity. Productive workers are company's assets to maintain company performance. Indeed, the higher skill workers make production process more efficient. Often employers provide opportunities for their employees to participate in employee training so that the workers' skills increase. Meanwhile, the government also has an interest in providing productive workers to support economic development activities.

Furthermore, one of the main problems in employment in Indonesia is low labour productivity. Frequently, low productivity is associated with education levels. The higher the level of education of a person, the higher the level of productivity that might be achieved. Perhaps the ability to read and write is one of the essential elements of the early stages of the industrialisation program. At a higher level of industrialisation, more advanced technical skills are needed.

Petrakis and Stamatakis (2002) report that primary and secondary education is more important for growth in less developed countries than they do in developed countries, where higher education is of greater importance. However, the impact of human capital is not limited to one particular area: human capital in one region can also influence its neighbours. Various studies in the urban field (Rosenthal and Strange, 2008) and regional (López-Bazo et al., 2004; 
Fingleton and López-Bazo, 2006;) economies seem to confirm the existence of positive externalities of human capital. A region benefited in line with externalities of human capital occurred in another region.

Another infrastructure that determines the growth of a region is the road infrastructure and health facilities. Infrastructure development is an integral part of national development. Infrastructure is the driving force of economic growth. Transportation sector activities are the backbone of the distribution pattern of both goods and passengers. Another infrastructure such as electricity and telecommunications related to the nation's modernisation efforts and its provision is one of the most critical aspects to increase the productivity of the production sector. Availability of housing and settlement facilities, including drinking water and sanitation, widely and evenly, and sustainable management of water resources determines the level of community welfare. Conversely, delays in the construction of new infrastructure can hamper the pace of national development.

Moreover, infrastructure has an equally important role to strengthen national unity. Transportation and telecommunication networks are one of the regional gateways. Infrastructure is a trigger for the development of an area. Inter-regional welfare disparities can also be identified from infrastructure gaps that occur among them. Regional-based infrastructure development is increasingly important to pay attention to. Experience shows that transportation infrastructure plays a major role in opening up the isolation of the region, and the availability of irrigation is a prerequisite for the success of agricultural development and other sectors.
The availability of road infrastructure can affect the ability of the region in carrying out its economic activities. As one of the transportation infrastructure, roads are the means of transportation used to support short-term transport within a region. Road construction can provide an increased competitive advantage of a region.

The improvement of road facilities increases the efficiency of transportation so that it solves the problem of high-cost distribution. A better transportation system will make the goods mobility faster and cheaper. More goods and services can be produced by a region, although the number of labour is unchanged. Therefore, a better transportation system leads to an increase in productivity.

Furthermore, the development of human resources can also take the form of development in the health sector. Investments in the health sector can be in the form of repair or addition of health facilities. Health facilities are health infrastructure that can be accessed by the community. The health infrastructure development is one of the efforts that can be done to ensure the availability of health services for the community. The areas with good health infrastructure are expected to provide adequate health services to their communities.

The development of health infrastructure will improve public health. Healthy communities are expected to work more productive, to produce output or income as well. Improvements in health lead to an increase in income per capita directly as each can produce more per unit of labour input (Acemoglu and Johnson, 2006). Individuals who are healthier have higher returns to labour input. Conversely, poor health can reduce aggregate productivity. Therefore, the 
poor health to be a key factor in reducing aggregate productivity, thus explaining the existence of persistent underdevelopment in many regions of the world (Cole and Neumayer, 2007).

Moreover, the infrastructure development will increase the amount of capital, so that increase the productivity of the economy. Infrastructure development is an integral part of national development. Infrastructure is the driving force of economic growth. Transportation sector activities are the backbone of the distribution pattern of both goods and passengers. Another infrastructure such as electricity and telecommunications related to the nation's modernisation efforts and its provision is one of the most critical aspects to increase the productivity of the production sector.

Availability of housing and settlement facilities, including drinking water and sanitation, widely and evenly, and sustainable management of water resources determines the level of community welfare. Conversely, delays in the construction of new infrastructure can hamper the pace of national development.

Moreover, infrastructure has an equally important role to strengthen national unity. Transportation and telecommunication networks are one of the regional gateways. Infrastructure is a trigger for the development of an area. Inter-regional welfare disparities can also be identified from infrastructure gaps that occur among them. Regional-based infrastructure development is increasingly important to pay attention to. Experience shows that transportation infrastructure plays a major role in opening up the isolation of the region, and the availability of irrigation is a prerequisite for the success of agricultural development and other sectors.

The Infrastructure development, especially in lagging areas, will have a multiplier impact on the region's economy to catch up with the advanced areas. Given the higher rate of economic growth, the economies of the previously lagging regions are capable of catching up with the advanced ones (Barro and Sala-i Martin, 2004). Thus there has been a convergence marked by the decrease in the disparity between regions.

Convergence refers to Neo classical economic growth theory based on several assumptions, namely: (1) commodity markets are single, (2) there are two factors of production, (3) labor and capital in full employment conditions, (4) there is a substitution between capital and labor work, (5) the mobility of production factors is free. Neo classical economic growth theory states that the gap that arises due to differences in the ratio of labor-capital between regions will increasingly decrease. The process to balance leads to steady-state conditions assuming a constant yield scale. In this process short-term productivity differences, which are caused by differences in production technology, will shrink and gradually these differences disappear as capital and labor move freely between regions. This free movement of production factors will equal the value of marginal products.

Moreover, there are 2 (two) concepts of convergence, namely $\sigma$ convergence and $\beta$ convergence. The concept of $\sigma$ convergence refers to the dispersion that can be measured by, for example, the standard deviation of the revenue logs or per capita products between regions. If the value shows a decrease, then there has been the convergence of income and vice versa. Meanwhile, the concept of $\beta$ 
convergence states that a weak economy can catch a prosperous economy in terms of per capita income (Barro and Sala-i Martin, 2004). The concept of $\beta$ convergence is divided into 2 (two) namely absolute convergence and conditional convergence. Absolute convergence refers to the measurement of convergence based on initial income levels alone. The absolute convergence measurements are made without including the control variables that are characteristic of each region. Each region is considered to have the same steady state conditions so that the calculation of convergence does not include other variables such as investment and growth of different populations between regions. Meanwhile, the calculation of conditional convergence is carried out by including the influence of infrastructure and other variables (control variables) which are expected to affect the steady state conditions of each region. To analize the effect of infrastructure and other variables on the steady-state conditions, the conditional convergence is performed.

Besides an income convergence, a muchdiscussed issue is productivity convergence. The advancement of a region is determined by the productivity of human resources in this area. Productivity is a significant factor in the progress of an area. There has been little empirical work examining productivity convergence among firms. For these few studies at the firm level, most focus on how firms converge to their national frontier (Nishimura et al., 2005; Girma and Kneller, 2005; Chevalier et al., 2012), while the issue of productivity convergence to regional frontier has tended to be ignored. Regional productivity convergence is important because firms located in the same region share many common local characteristics, such as language, culture, and natural resource, which might facilitate productivity convergence (Lancheros, 2015).

Given this, it is expected that the speed of convergence is faster to regional frontier than to the national frontier. On the other hand, the distance to national frontier is generally larger than to regional frontier, which provides more scope for convergence, and the regional frontier is not advanced enough for firms to converge. The convergence speed is faster to the regional frontier than to national frontier, because knowledge spillovers may be to some extent geographically concentrated, so firms benefit more from frontiers that are located nearby.

Regional productivity has significant implications for national and regional government policy making. Reducing income inequality and improving social welfare in disadvantaged areas depends on increasing production efficiency and labour productivity. Therefore, some researchers are interested in examining the productivity gap.

Some research on convergence productivity gives different results. The speed of productivity convergence also varies according to the level of aggregation. The convergence of labour productivity at the regional level occurs more rapidly than that at the national and industrial levels. Calculating the speed of convergence of labour productivity by taking account of structural changes will result in more precise estimates (Naveed, and Ahmad, 2016).

The labour productivity in Bulgaria has increased, leading to a convergence with labours' productivity in the European Union (Pritha Mitra and Cyril Pouvelle, 2012). Similarly, the results of research by Cette et al. (2012) show that disparities in productivity between firms are smaller indicating productivity convergence. The spread of 
inter-company productivity shows the difficulty of reallocating production factors, labour and capital, between firms. The results of research Mahmood (2012) in Europe shows the convergence in the primary sector and services. However, in the manufacturing sector, convergence is found for all industries except for the electronics and computing industry. In general, the speed of convergence estimation shows a gradual adjustment.

Meanwhile, Sondermann's study (2012) show evidence of a productivity convergence in the service and manufacturing sectors, although at the aggregate level no productivity convergence can be found. The results of the study in Peru also show the same phenomenon. Labour productivity in the manufacturing and mining sectors shows a convergence, but this study found no reliable evidence for productivity convergence in agriculture and services (Iacovone et al., 2015).

In contrast, some of the research results indicate the absence of productivity convergence (Ito, 2010; Männasoo et al. 2016). The results of Ito (2010) show an increase in the gap in Total Factor Productivity (TFP). Meanwhile, the results of the Männasoo et al. (2016) study show that productivity gaps in some EU countries are widening. This condition implies that far-flung areas show lagging economic structures that are unable to exploit and take advantage of increased levels of human resource qualification.

Furthermore, this research took the area of Gunungkidul Regency which covers 18 with Wonosari district which became the centre of government. In the formation of the gross domestic, regional product, the district Wonosari dominates the value added of Gunungkidul Regency. Economic activities are concentrated in the central part and wonosari district as the regency capital. The position of Wonosari district as the centre of government allows the development of the manufacturing sector and the service sector. In Wonosari district, the service sector is the dominant sector in the formation of the gross domestic, regional product. The hotels and restaurants sector, the transport and communications sector, financial sector, corporate lease and services sector are concentrated in Wonosari District. In 2016, nearly $17 \%$ of the economic contribution was contributed by Wonosari District. Meanwhile, $50 \%$ of the gunungkidul grdp was contributed by five districts namely wonosari, playen, ponjong, semanu, karangmojo and semin. Thirteen other districts only have 3 to $5 \%$ contribution respectively (Figure 1). The position Wonosari District of as the centre of economic activities allows the development of the tertiary sector, while other districts are still focused on the primary sector such as agriculture, and mining and quarrying sector.

Furthermore, the research with the data at district will be able to illustrate the presence or absence of productivity convergence more closely. Taking a narrower area of research can eliminate biases due to aggregation factors. With the microdata, it can be analysed the condition of each district in more detail so that it can be designed more appropriate policy according to condition and economic potency of each district. When productivity differences are identified, local government policies can be formulated more precisely so that the lagging district can pursue the advanced district through a process of economic growth. 


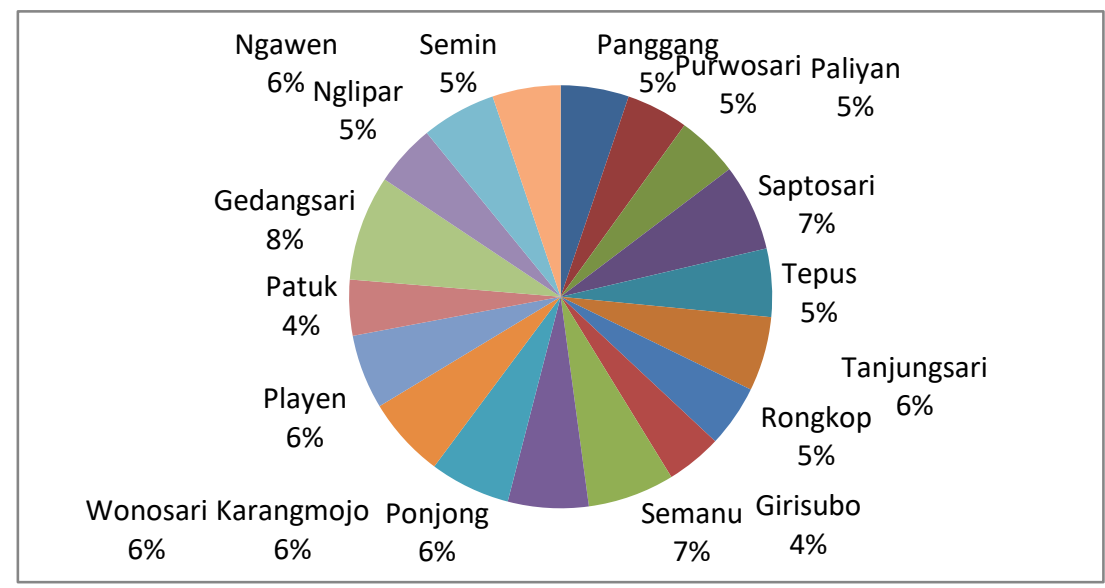

Figure 1. Distribution of GRDP at 2010 Constant Price by District, 2016 Sources : The Statistics of Gunungkidul

\section{RESEARCH METHODS}

This research is analytical research that aims to understand phenomena by discovering and measuring causal relations among them. The secondary data published by the Statistics of DIY is used in this study. The data includes labour productivity, educational facilities, health facilities and the length of roads in each district during the period 2009-2016. Selection of the starting point of research in 2009 is due to that this year began to change the economic structure marked by an increase in the share of services sector that has exceeded the share of the agricultural sector. The selection of the endpoint in 2016 due to the data in this year is the latest data.

Furthermore, the research defines labour productivity as the value of the Gross Regional Domestic Product (GRDP) of districts, in constant prices 2010, divided by the number of the labour force. Meanwhile, the educational infrastructure refers to a comparison between the number of pupils and the number of teachers. The total number of health personnel is the total number of health personnel including public and private employees working in health centres, hospitals, or health clinics in each district.
The road infrastructure refers to the length of road with right conditions in each district.

The convergence study can be done using time series data, cross section data, or panel data. Use of cross section data in the study convergence according to Islam (2003) contains weaknesses because of cross section data is a data point that is data at a certain point in time while a lot of diversity between regions (heterogeneity). In addition, with data cross section technological factors for each region is considered the same.

This research uses a regression analysis. The data covers labour productivity in every district in Gunungkidul region and the variables influencing it during the 2009-2016 period. Thus, the research data is the dynamic panel data. Panel data has several advantages over cross-sectional data or time series data. These include the following (Baltagi, 2005) (1) Controlling for individual heterogeneity. Panel data suggests that individuals, firms, states or countries are heterogeneous. Time-series and cross-section studies not controlling this heterogeneity run the risk of obtaining biased results, (2) Panel data give more informative data, more variability, less collinearity among the variables, more degrees of freedom and more 
efficiency, (3) Panel data are better able to study the dynamics of adjustment, (4) Panel data are better able to identify and measure effects that are simply not detectable in pure cross-section or pure time-series data, (5) Panel data models allow us to construct and test more complicated behavioral models than purely cross-section or time-series data.

The use of dynamic model able to describe the real condition in the field given that the interaction between economic variables rarely that is instantaneous. Frequently, the dependent variable reacts to the independent variable with a time interval (lag). The dynamic model can make static theories to be dynamic by explicitly taking into account the time element.

In the formation and estimation of dynamic models, one integral part is the issue of cointegration. This approach is related to the possibility of a long-term balance relationship between economic variables as desired in economic theory. Cointegration testing aims to find out whether a set of variables is cointegrated or not. Cointegration refers to the idea that for a set of variables there is a linear combination of these variables which are stationary. The vector of slope coefficients that make stationary combinations is called cointegration vectors. If there is a cointegration relationship between two variables, then there is at least one long-term causality relationship in one direction between the two variables.

This study uses cointegration test based on Kao method. This method presents two tests for the null hypothesis of no cointegration in panel data: the DF and ADF type tests. Kao results are offered for the asymptotic of spurious regression within a panel data Setting. The specification of the panel model allows for differing intercepts across cross-sections and common slopes. Further, the long-run variance covariance matrix is assumed to be the same for all cross-section observations. These asymptotic results on the spurious regression are essential for testing the null hypothesis of no cointegration. Under the null of no cointegration the residuals required for the test need to be estimated, by construction, from a spurious regression. Note that the residual based test is equivalent to testing for a unit root in the $L S D V$ estimated residuals. Using the panel model, the $D F$ and $A D F$ test statistics, after appropriate normalizations will converge in distribution to random variables with normal distributions (Barbieri, 2006).

Hereafter, the research model is formed in a dynamic panel data by inserting lag on both the right and left sides of the equation. To get a simple model, then the reduction is made from the most extended lag to the shortest lag to get the desired model. The regression model estimate of productivity convergence is written in the following equation.

$$
\begin{gathered}
\Delta \ln Y_{i t}=\alpha_{i}+\omega \ln Y_{i, t-1}+\sum_{j=0}^{k} \beta_{i j} \ln X_{1 i t-j}+ \\
\sum_{j=1}^{k} \gamma_{i j} \ln X_{2 i t-j}+\sum_{j=\mathrm{o}}^{k} \delta_{i j} \ln X_{3 i t-j}+e_{i t}
\end{gathered}
$$

Respectively, $\mathrm{Y}$ is the labour productivity, $\mathrm{X}_{1}$ is the pupil-teacher ratio, $\mathrm{X}_{\mathbf{2}}$ refers to the number of health personnel, and $\mathrm{X}_{3}$ is the length of the road in good condition.

Generally, a panel regression consists of fixed effects model and random effects model. The use of so many dummy variables in the fixed effects model will have an impact on the reduced degree of freedom. Based on this consideration, the random effects model has advantages. However, the fixed effects model also has other advantages. In fixed 
effects models there is no need to justify treating individual effects not correlating with independent variables as assumed in the random effects model. Consistency in the random effects model decreases when several variables correlate with individual effects.

Moreover, to choose the best model whether the fixed effect model or random effects this research use the Hausman test. This test will examine hypotheses which state that the individual effects correlate with independent variables. If the individual effects correlate with regressors, then it violates one of the Gauss-Markov assumptions so that the selected model is fixed effects. The Hausman test follows a ChiSquare distribution with the degree of freedom according to the number of independent variables.

The analysis in Equations (1) provides an overview of the productivity convergence. This convergence occurs when the coefficient $\omega$ is negative $(\omega<0)$. The speed of convergence $\lambda$ at which the productivity level is converging to a uniform productivity level can be calculated according to $\lambda=$ $-\left[\left(\frac{1}{T}\right) \ln (\beta+1)\right]$. $T$ denotes the length of the time interval under consideration. A convenient way to express the speed of convergence is the time needed for the productivity level to move half its initial level o $y$ and steady-state productivity level (Mahmood,
2012). The time it takes to close half of the initial gap called half-life of convergence is calculated by following equation (Jan dan A.R. Chaudhary, 2011).

$$
H=\frac{\operatorname{Ln} 2}{\lambda}
$$

\section{RESULTS AND DISCUSSION}

One way to find out whether there is inequality between districts is to use a descriptive table. Descriptive statistics are useful for describing the basic features of data, for example, the summary statistics for the scale variables and measures of the data. Meanwhile, Table 1 presents descriptive statistical indicators of the variables. Based on descriptive data, there is an inequality between districts in Gunungkidul district. The difference between the maximum value and the minimum value is significant enough to indicate the imbalance between the developed region and the lagging regions. This inequality is reflected in the value range of worker productivity, educational facilities, health facilities, and the length of the road. Likewise, there is unbalance in infrastructure across districts. The educational facilities, health facilities and the length of roads varies across district. The excellence infrastructure is located in central part of Gunungkidul Regency such as Wonosari and Playen. Most of doctor and dentis stay and operate in these districts.

Table 1. Descriptive Statistic of Variables, 2009-2016

\begin{tabular}{lcccc}
\hline & $\begin{array}{c}\text { Labour } \\
\text { Productivity }\end{array}$ & $\begin{array}{c}\text { Education } \\
\text { Facilities }\end{array}$ & $\begin{array}{c}\text { Health } \\
\text { Facilities }\end{array}$ & $\begin{array}{c}\text { Length of } \\
\text { Roads }\end{array}$ \\
\hline Mean & 8.03 & 12.49 & 4.78 & 22.75 \\
Median & 7.86 & 11.00 & 3.00 & 20.59 \\
Maximum & 13.10 & 34.00 & 74.00 & 48.75 \\
Minimum & 5.08 & 7.00 & 1.00 & 10.04 \\
Observation & 144 & 144 & 144 & 144 \\
\hline
\end{tabular}


According to the size of Gross Regional Domestic Product (GRDP) per capita, there are some districts with high per capita GRDP comprise Wonosari, Nglipar and Playen, and some districts with low per capita GRDP comprise Karangmojo, Ngawen, Paliyan, Tepus, and Gedangsari. This imbalance occurred due to the heterogeneity of infrastructure and diversity of economic sectors. The area that is still lagging behind is the southern part of Gunungkidul Regency, which has the characteristics of mountains and coastal areas. The southern part still lacks infrastructure facilities, minimal growth centers and high geographical barriers. The southern part needs other sector options to improve its economic development in addition to the agricultural sector. Tourism can be a leading sector in the southern part of Gunungkidul. This area has many beautiful beaches. However, in the southern region of Gunungkidul, the construction of large hotel is difficult because the area is a protected geological area. Therefore, building large-scale hotels in the southern region will threaten the presence of karts.

Furthermore, this study uses Kao cointegration test to find out whether a set of variables is cointegrated or not. Based on the Kao cointegration test there is a linear combination of variables in the model that is stationary. The magnitude of ADF shows a value of -2.212 with a $\mathrm{p}^{-}$value is less than o.05. This result means that the residual resulted from the regression estimation is stationary $I(o)$. The variables in the model have a long-term equilibrium relationship in line with the economic theory. The estimated model has a consistency in the long run, or at least there is a causality relationship in one direction between the variables in the model (Table 2).
Table 2. The Results of Kao Cointegration Test

\begin{tabular}{ccc} 
& t-Statistic & Prob. \\
\hline ADF & -2.212 & 0.014 \\
\hline
\end{tabular}

Furthermore, to obtain a simple model, the lag selection is made by using the Akaike criterion (Liew, 2004). A smaller value of the Akaike (AIC) criterion indicates a better model. Based on the VAR estimation result, the minimum AIC value for the model occurs when the lag length is one year. The VAR with length lag one will be spared from the model specification error and freedom degree reduction problem. The VAR with length 1 is parsimonious VAR.

Likewise, the Hausman's test shows that the Chi-Square Statistic is significant. The magnitude of Cross-section random shows a value of 9.237 with a p-value is less than 0.05. This result means that the individual effects are correlated with independent variables, so that do not meet one of the Gauss-Markov assumptions. Therefore, the fixed effects model is superior to the random effects model (Table 3).

Table 3. The Results of Hausman Test

\begin{tabular}{lccc}
\hline Chi-Square Statistic & Chi-Sq. & d.f. & Prob. \\
\hline Cross-section random & 9.237 & 3 & 0.026 \\
\hline
\end{tabular}

Moreover, based on estimation with fixed effects model and reduction of insignificant parameters, it is obtained simple estimation results. The value of adjusted R-squared of 0.5401 indicates that the variation of independent variables can explain as much as 54.01 per cent of the variation in labour productivity, while the remaining 45.09 per cent is explained by the residual. Meanwhile, the high F-value indicates that the independent variables 
simultaneously affect the dependent variable (Table 4).

Table 4. Estimated Result (Fixed Effects)

\begin{tabular}{clcc}
\hline No & Variable (in a log) & Coefficient & $\begin{array}{c}\text { Standard } \\
\text { Errors }\end{array}$ \\
\hline 1 & $\begin{array}{l}\text { Labour Productivity } \\
\text { (previous year) }\end{array}$ & $-0.272^{*}$ & 0.023 \\
2 & Education Facilities & $-0.013^{*}$ & 0.005 \\
3 & Health Facilities & $0.018^{*}$ & 0.005 \\
4 & Length of Roads & $0.097^{*}$ & 0.037 \\
5 & Constant & $0.304^{*}$ & 0.106 \\
\hline
\end{tabular}

Outcome: Change in log (Productivity)

Adjusted- $R^{2}=0.5401 ; F=7.989$

* Significant at $(\alpha=5$ per cent)

The result of conditional convergence analysis shows that the regression coefficient of labour productivity (previous year) is negative. There is a process of labour productivity convergence among districts in Gunungkidul Regency. The growth of labour productivity in the lagging district can pursue the labour productivity in the advanced region. Thus the labour productivity gap between districts will disappear. The local government has done infrastructure development to facilitate economic activity. However, the local government realises that its area is extensive with hilly topography. Therefore, the development of road infrastructure needs to be improved so that the local access to the centres of economic activity is opened. Open access to markets allows farmers and small business actors to sell their products.

The multiplier effect of road infrastructure development is enormous. Infrastructure development such as the construction of the South Cross Road supports the development of the southern zone which is a potential region of the tourism sector. The districts included in this zone have tourism beaches that are very supportive of the economic progress of the local area such as
District Panggang, Purwosari, Saptosari, Tepus, Tanjungsari, and Girisubo. The tourism development has an impact on the development of other sectors such as trade, hotels, restaurants, transportation and communications and services. Infrastructure development, especially in lagging areas, will have a multiplier impact on the district's economy. The labour productivity in lagging areas increases rapidly to catch up with advanced ones. Therefore, the labour productivity among district tends to convergence.

The level of labour productivity convergence in Gunungkidul Regency is 0.045. This level shows that the speed of each district to achieve steady state is 4.5 per cent per year. The time to close half the initial gap or halflife of convergence is more than 15.4 years. The ongoing infrastructure development is a factor that accelerates the convergence process. For comparison, the speed of convergence of labour productivity in European countries found by Mahmood (2012) is 18 per cent per year. The different convergence of the previous research is thought due to differences in the scope of the study. Mahmood (2012) uses a country-level database, while this study uses data based on the district level.

The coefficient of education variables of -o.o13 indicates that if the ratio of pupils to teacher decreased by 1 per cent will be followed an increase in employee productivity by 0.013 per cent (all other things being equal). The decrease in the ratio of student to teacher shows improvement towards the ideal ratio. Therefore, the process of knowledge transfer will become faster to produce better qualified graduates.

This results support the results of research Ozturk (2001) which states that education in every sense is one of the 
fundamental factors of development. Education enriches people's understanding of themselves and the world. It improves the quality of their lives and leads to broad social benefits to individuals and society. Education raises people's productivity and creativity and promotes entrepreneurship and technological advances. Besides, it plays a very crucial role in securing economic and social progress and improving income distribution.

Education progress directly contributes to the development of human resources quality. Indeed, education is closely related to economic activity. The development of educational infrastructure in lagging areas will be able to produce productive labour so that this region will be able to catch up from advanced ones. Therefore, improvement of educational infrastructure supports the convergence of labour productivity.

The local government intends to improve the quality of human resources in order to realise a competitive region. This mission is the effort of the Government of Gunungkidul Regency to build quality and competitive human resources in all fields through human investment as the central pillar of regional development. Through improvement in education system, the local government want to improve the quality of human capital.

Human capital is a workforce that has high knowledge and is a production factor that plays an essential role in economic growth. Economic growth can no longer rely on the factors of production in the form of money and land capital, but there has been a shift in which human capital has become an essential production factor to achieve sustainable economic growth and weapons for a country to win a global competition.
Investment in education is considered to have positive implications for the addition of resources to the economy, to increase output in general. For education, workers will provide knowledge about the implementation of work tasks while providing a basis for developing themselves and the ability to use all means for the smooth work. Education will shape and improve one's knowledge so that they can do work faster and precisely. The higher one's education, the higher the productivity. Considering that the education sector is a part of essential services that significantly determines the quality of human resources, the local government always strives to provide the broadest possible access to citizens for the completion of the national 9-year compulsory education program and supports the national 12-year compulsory education program.

Education is closely related to the quality of human resources as a factor of production to produce output. The higher the quality of human resources, the higher the efficiency and productivity of the economy. The fact shows that the state that emphasises the development paradigm with the dimensions of human resources has been able to develop even though it does not have abundant natural resource wealth. Emphasis on human investment (human investment) is the basis for increasing the productivity of total production factors. Other production factors such as land, labour, physical capital can experience diminishing returns, but science and technology have never experienced it. Science and technology are always able to produce innovations to support economic growth.

Education is needed to support the sustainability of economic development. Higher education broadens people's know- 
ledge and enhances the rationality of their thinking. Indeed, higher education allows people to reason in acting and thinking for progress. Higher knowledge supports the emergence of reforms in engineering, economics, and various other aspects of life. Furthermore, education allows people to learn the technical knowledge needed to run a modern company and other modern activities as a result of innovation.

Regional development policies that do not emphasise on improving human quality will make the area left behind from other regions. Improving the quality of human capital will also provide benefits in reducing inequality between regions. The benefits of human capital have a broad influence on the economy including the development of adaptability and allocation efficiency.

Economic growth is not solely determined by the accumulation of capital investment but also by human investment. Capital investment and human investment are two things that complement each other. The development of human capital can not only increase productivity and economic growth but also play an important role in income distribution. For this reason, poverty alleviation strategies must rely on the development of human capital.

The contribution of human capital accumulation in growth is increasingly essential. Economic activities caused by the ability of innovation will produce efficient economic activity so that it can shift activities that have so far relied on capital accumulation. The emergence of land transportation based on networks can shift the dominance of land transportation which is based on capital accumulation. Thus the main difference in living standards between countries comes from differences in human capital. Human capital is not only identified as a critical contributor to economic growth but also encourages development goals to improve human quality in general. The focus of global development in the millennium development goals (MDGs) also positions the improvement of the quality of human capital as the main priority.

Indeed, the importance of human capital for economic growth has been highlighted in some studies. That countries and regions with higher levels of human capital can expect higher rates of growth than lowerlevel regions. However, despite the theoretical predictions of these models, empirical evidence cannot be concluded with research reporting non-significant or even negative effects of human capital on growth (de la Fuente and Doménech 2006).

Another factor in improving the quality of public health services. Through various program policies and activities, the local government seeks to improve the quality and health services that are increasingly affordable to all levels of society. In general, the development of the health sector aims to increase awareness, willingness and ability to live healthily for each person in order to realise an optimal level of community health. Health development is an investment to improve the quality of human resources aimed at achieving a better level of health. An adequacy of health workers with communities served both in quantity and quality will provide a higher level of satisfaction.

The success of health sector development is reflected in, among others, life expectancy. This indicator can represent the output of comprehensive health care efforts. If a person has a better health status, the person concerned will have the opportunity 
to have a more extended age or have a high life expectancy. Life expectancy is a useful indicator for evaluating government performance in improving the welfare of the population in general, and improving public health in particular. The higher life expectancy in a region reflects the excellent quality of health development in the region.

Public health services are realised by the government by adding health facilities and services such as building health centre facilities and infrastructure and add doctors and other health workers. The government health service facilities in Gunungkidul Regency consist of 30 health centres and 110 sub-health centres. Of the 30 Puskesmas, 14 of them were Puskesmas with inpatient services and 16 Puskesmas non-care with standard delivery services. In addition to government health service facilities, in the Gunungkidul Regency also has many private healthcare facilities which include: private hospitals and practising doctors. In the health sector, there are also supporting health facilities such as pharmacies and clinical laboratories.

Health services in Gunungkidul Regency can be accessed by the poor and non-poor who live in the region Gunungkidul Regency and in various surrounding areas Gunungkidul or border area. The poor who can access health services in government agencies is those who are registered with Jamkesmas. For the poor who are not included in Jamkesmas, Jamkesos funds have been provided through the Province Government Budget. Since the end of 2011, Gunungkidul has developed a guarantee of universal health services (Jamkesta) provided through the district budget. The service facilities in collaboration with Jamkesta are Puskesmas and several hospitals in the Yogyakarta
Special Regions area.

Moreover, regarding service, the quality of service is the main thing that determines customer satisfaction. Customers in Puskesmas include internal customers (employees of Puskesmas) and external customers (community). In order to meet the quality standards of health services at the Puskesmas, several Puskesmas have been implemented by the ISO system. A total of 5 (five) Puskesmas have obtained ISO certificates, namely: Ponjong I, Nglipar I, Wonosari I, Patuk I and Panggang II. For other Puskesmas pioneered with the application of the ISO model, two Puskesmas were chosen (Panggang I, Karangmojo II, Rongkop and Semin I). The primary health care facilities in Gunungkidul Regency have spread throughout the districts.

Besides physical infrastructure, what is no less important is human resources working in the health sector. Health workers are those who work in government health agencies and have a health education background Health human resources include doctors, midwives and nurses. Health workers in Gunungkidul Regency are spread in the Health Office, Wonosari Regional General Hospital, Puskesmas and UPT Laboratory. However, regarding the availability of doctors, the problems that occur are the uneven distribution of doctors. Most doctors are in Wonosari and Playen Districts, while in other districts the number of doctors is relatively small. For this reason, the distribution of doctors is being sought to make it more evenly distributed.

Meanwhile, health infrastructure has a positive effect on labour productivity. The coefficient of health infrastructure of 0.018 indicates that if the number of health personnel increased by 1 per cent will lead to 
an increase in labour productivity by 0.018 per cent (all other things being equal). The development of health infrastructure will improve public health. Healthy communities are expected to work more productive, to produce output or income as well. This result supports the findings of Acemoglu and Johnson (2006) which states that improvements in health lead to an increase per capita income directly so that each can produce more output. Individuals who are healthier have higher returns to labour input.

Furthermore, the road length has a positive regression coefficient on labour productivity. The regression coefficient of road length is 0.097 so that the increase of road length by 1 per cent causes the increase of work productivity by 0.097 per cent (all other things being equal). Improvement of road facilities increases the efficiency of transportation. An efficient transportation system will solve the problem of high-cost distribution. The mobility of goods and people can take place quickly and cheaply. A region can produce more goods and services. The improvement of road infrastructure increases worker productivity.

This finding is in line with Del Bo et al. (2010) which confirmed that there is a positive relationship between road infrastructure and economic development. The research results also support Yang's (2017) finding that highways promoted growth of aggregate productivity by facilitating firm entry, exit and reallocation. Eliminating all highways in China would decrease aggregate productivity by 3.2 per cent.

Improved road facilities, especially in underdeveloped areas, can accelerate economic activity in this regions. An efficient transportation system will solve the problem of high-cost distribution. The mobility of goods and people can take place quickly and cheaply. Therefore, development of road infrastructure increases productivity. This increase is characterised by an increasing number of goods and services that can be produced by a region.

In line with regional development, the regions in Gunungkidul in principle have different development characteristics. In this regard, the Gunungkidul region has an attractive condition, where Wonosari District is the centre of growth which is currently growing and developing naturally, spreading to the surrounding areas. The development of regional functions following the hinterland function in the vicinity of Wonosari District such as Patuk, Karangmojo, Semanu and Tanjungsari Districts is in principle an essential part of supporting the development of the region in Gunungkidul. In the end, the hinterland's carrying capacity for economic growth and the improvement of community welfare in Gunungkidul can be formed. The development of infrastructure from and to the hinterland provides an essential role in increasing trade value.

On the other hand, for Wonosari District also must provide an essential role in supporting the hinterland both in the development of educational services and the provision of goods and commodities from other regions to support the hinterland regions as part of Gunungkidul sub-centre of growth.

Consideration of the regional policy direction provides an essential role in increasing people's purchasing power because with a good pattern of commodity and commodity distribution management, and the pattern of market price regulation by the government will increase the income of farmers, fishers, traders and other elements 
of society. Meanwhile, from the aspect of commodity fulfilment, it is fulfilled properly, and the community has a good purchasing power of commodities sold in the market. Furthermore, with the pattern of creating a commodity distribution chain in circulation and meeting the needs of the population, especially the Gunungkidul community, it will also have implications for the fulfilment of the provision of community employment.

Such a management pattern will provide the role of local commodities circulating individually in the Gunungkidul region which will provide higher benefits to the community and have a multiplier impact on the economic performance of Gunungkidul. Support for infrastructure development will have an effect on increasing access, as well as the distribution and marketing of commodities in Gunungkidul, as well as giving influence also to increase economic growth in the district of Gunungkidul. Infrastructure in the hinterland region was developed to provide connectivity support with a growth centre which in this case is Wonosari District.

In order to improve the transportation system, the government construct the South Cross Road that connected the regencies of Kulon Progo-Bantul-Gunungkidul. This construction is part of an effort to develop the southern of Yogyakarta Special Region for compensating development of the region in Java that previously tends to be concentrated only in the northern part of Java. The South Cross Road was built stretching from Banten Province to East Java Province. Besides, the benefits gained from the construction of the South Cross Road, Gunungkidul Regency is benefited by the raising of economic activities in Yogyakarta Special Region.
The South Cross Road is a road that falls into the category of arterial roads. As the road in general, this road is a primary arterial road that connects national activity centres with regional activity centres. Around The South Cross Road, economic activities have emerged that have been able to improve the welfare of its citizens.

\section{CONCLUSION}

The result shows that there is a process of convergence of labour productivity among districts in Gunungkidul Regency. The speed of each district to achieve steady state is 4.5 per cent per year. Also, the time to close half the initial gap or half-life of convergence is more than 15.4 years The labour productivity, in the lagging districts, tends to grow faster than the advanced ones. Thus, the labour productivity gap between districts will disappear.

The infrastructure development increases the amount of capital, and in turns, it increases labour productivity. A better educational facility supports the speed of the knowledge transfer process to generate productive labour. Meanwhile, the development of health facilities will improve public health. A healthy workforce will work quickly so that labour productivity increases. Furthermore, road infrastructure has a positive effect on labour productivity. Improvement of road facilities solves the problem of high-cost distribution so that the output increase although the quantity of labour is unchanged.

This research also highlights that local governments should improve the human resources by providing better facilities in education and health. Qualified labour is expected to work more productively. Also, this finding emphasises the importance of 
road facilities to reduce the high cost of distribution so that increase labour productivity.

The following research can examine the convergence of labour productivity by incorporating factors of economic structural change. Many districts have experienced changes in the economic structure. Initially the economy is dominated by the primary sector, however along with technological progress, currently, the economy is dominated by the tertiary sector.

\section{REFERENCES}

Acemoglu, D. and Johnson, S., 2006. Disease and Development: The Effect of Life Expectancy on Economic Growth. NBER Working Paper Series, No.12269.

Baltagi, Badi, 2005. Econometric Analysis of Panel Data, John Wiley \& Sons Ltd.

Barbieri, Laura, 2006. Panel Cointegration Tests: A Review, Università Cattolica del Sacro Cuore, Piacenza

Barro, Robert J. and Xavier Sala-i Martin. 2004. Economic Growth and Edition. MIT Press, London.

Chevalier, P.-A., Lecat, R. \& Oulton, N. 2012. Convergence of Firm-Level Productivity, Globalisation and Information Technology: Evidence from France. Economics Letters, 116.

Cole Matthew A. and Eric Neumayer, 2007, The Impact of Poor Health on Total Factor Productivity, Journal of Development Studies, 42(6), pp. 918-938

Del Bo, Chiara, Massimo Florio, and Giancarlo Manzi. 2010. Regional Infrastructure and Convergence: Growth Implications in a Spatial Framework, Transition Studies Review, 17(3), pp. 475-493.

de la Fuente A., and Doménech R. (2006) Human Capital In Growth Regressions: How Much Difference Does Data Quality Make? Journal of the European Economic Association 4(1): 1-36.

Cette, Gilbert, Simon Corde and Rémy Lecat, 2012, Firm-level Productivity Dispersion and Convergence Working Papers of the Banque de France.

Fingleton B, and López-Bazo E. (2006) Empirical Growth Models With Spatial Effects. Papers in Regional Science 85 (2): 177-219.

Girma, S. \& Kneller, R. 2005. Convergence in the UK Service Sector: Firm Level Evidence, 1988-1998.
Scottish Journal of Political Economy, 52(5), 736746.

Iacovone, Leonard, Luis F. Sánchez-Bayardo and Siddharth Sharma, 2015. Regional Productivity Convergence in Peru, Policy Research Working Paper 7499 .

Islam, N., (2003), "What Have We Learnt From The Convergence Debate?", Journal of Economic Survey, 17 (3), 309-362.

Ito, Tadashi 2010. NAFTA and Productivity Convergence between Mexico and the US, Cuadernos de Economía, 47 (Mayo), pp. 15-55.

Jan, Sajjad Ahmad dan A.R. Chaudhary. 2011. Testing the Conditional Convergence Hypothesis for Pakistan. Pak. J. Commer. Soc. Sci., 5(1), pp. 117128.

Lall, S., Z. Shalizi, and U. Deichmann, 2004. Agglomeration Economies and Productivity in Indian Industry, Journal of Development Economics, 73(2), pp. 643-673

Lancheros ,Sandra and Chris Milner, 2015. Globalisation and Regional Productivity Convergence: A Firm-level Analysis from India, Working Paper, University of Nottingham Ningbo China and GEP.

Liew, V.K. S., 2004. Which Lag Length Selection Criteria Should We Employ? Economics Bulletin, 3(33), pp. 1-9.

López-Bazo E; Vayá E, Artís M (2004) Regional Externalities and Growth: Evidence from European Regions. Journal of Regional Science 44 (1): 43-73

Mahmood, Tahir, 2012, Labour Productivity Convergence in 52 Industries: A Panel Data Analysis of Some European Countries, International Journal of Economics and Financial Issues, 2(3), pp. 320-339

Männasoo, Kadri, Heili Hein And Raul Ruubel, 2016. Regional Productivity Convergence In Advanced And Emerging European Economies, European Policy Analysis, 12.

Mitra, Pritha and Cyril Pouvelle, 2012. Productivity Growth and Structural Reform in Bulgaria: Restarting the Convergence Engine, IMF Working Paper European Department.

Naveed, Amjad dan Nisar Ahmad, 2016, Labour Productivity Convergence and Structural Changes: Simultaneous Analysis at Country, Regional and Industry Levels, Economic Structures, 5(19), pp. 117

Nishimura, K. G., Nakajima, T. \& Kiyota, K. 2005. Productivity Convergence at the Firm Level University of Tokyo MMRC Discussion Paper No. 39.

Ozturk, Ilhan, 20o1. The Role of Education in Economic Development: A Theoretical Perspective, Journal 
of Rural Development and Administration, 33(1), pp. 39-47.

Petrakis P E, Stamatakis D (2002) Growth and Educational Levels: A Comparative Analysis. Economics of Education Review 21 (5): 513-521

Rosenthal S S, Strange W C (2008) The Attenuation of Human Capital Externalities. Journal of Urban Economics 64 (2): 373-389
Sondermann, David, 2012. Productivity in The Euro Area: Any Evidence of Convergence? European Central Bank, Working Paper Series No 1431

Wilkinson, R. and Pickett, K., 2011, The Spirit Level, Bloomsbury Press Kim.

Yang, Yang, 2017. Transport Infrastructure, City Productivity Growth and Sectoral Reallocation: Evidence from China, RIEI Working Papers 2017o8, Xi'an Jiaotong-Liverpool University. 